Meta

Journal des traducteurs

Translators' Journal

\title{
Abstract Writing: English-Speaking Countries vs. Greece
}

\section{Maria Sidiropoulou}

Volume 40, numéro 4, décembre 1995

URI : https://id.erudit.org/iderudit/004140ar

DOI : https://doi.org/10.7202/004140ar

Aller au sommaire du numéro

Éditeur(s)

Les Presses de l'Université de Montréal

ISSN

0026-0452 (imprimé)

1492-1421 (numérique)

Découvrir la revue

Citer cet article

Sidiropoulou, M. (1995). Abstract Writing: English-Speaking Countries vs. Greece. Meta, 40(4), 579-593. https://doi.org/10.7202/004140ar

\section{Résumé de l'article}

À partir des résumés de communications des actes du $9{ }^{\mathrm{e}}$ World Congress of Applied Linguistics tenu à Athènes, on étudie les différentes tendances des chercheurs des pays anglo-saxons, d'une part, et de la Grèce, d'autre part, en tenant compte des intentions de l'auteur et de son attitude face au public.
Ce document est protégé par la loi sur le droit d'auteur. L'utilisation des services d'Érudit (y compris la reproduction) est assujettie à sa politique d'utilisation que vous pouvez consulter en ligne.

https://apropos.erudit.org/fr/usagers/politique-dutilisation/ 


\title{
ABSTRACT WRITING: ENGLISH- SPEAKING COUNTRIES VS. GREECE
}

MARIA SIDIROPOULOU

University of Alhens. Alhens. Greece

\begin{abstract}
Résumé
À partir des résumés de communications des actes du 9 - World Congress of Applied Linguistics tenu a Athenes. on étudie les différentes tendances des chercheurs des pays anglo-saxons, d'une part. et de la Gréce. d'autre part, en tenant compte des intentions de rauseur el de son atritude face au public.
\end{abstract}

\begin{abstract}
Cross-cultural variation in written discourse has attracted less attention than similar variation in oral communication, although such studies are useful in quite a few areas of application, especially translation. The article intends to investigate tendencies in abstract nriting bepween researchers from English-speaking coundries and Greece. The data come from the Proceedings of the 9th World Congress of Applied Linguistics held at ThessalonikiHalkidiki, Greece, in April 1990. Abstracts by Greek researchers are mostly written in English; it is assumed that internalized mother tongue preferences by Greek will be reflected in their n'riting in English. A sample of 100 abstracts is examined with respect to the aushors' intentions in writing them and their attitude towards the readership. The frame. norks assumed are B. Gros: and C. Sidner's theory of discourse structure (1985), P. Brow'n and S. Levinson's interactional model (1987) and B. Hatim and I. Mason's approach in translation (1990). The differences are of a pragmatic and communicative type: the two research groups differ in their preferences concerning the selection of discourse segments in the abstracts whereas their attitude tow'ards the readership is described by a different positive/ negative politeness pattern; no cultural group appears purely positively or negativety polite. Awareness of preferences in abstract writing facilitates both researchers and translators in achieving communicative and pragmatic equivalence in the target language.
\end{abstract}

\section{INTRODUCTION}

It is a common practice among sociolinguists to be concerned with the structure of social interaction manifested in conversation, usually working with transcribed spoken data. Abstracts are pieces of discourse intended to convey factual or propositional information, fulfilling the transactional - rather than interactional - (Brown and Yule 1983: 1) function of language. Although these message-oriented instances of language use are not expected to exhibit as much variation in structure as instances of the interactional function of language do, there do seem to be certain differences in their internal structuring and other linguistic choices. Structural variation in abstracts has concerned discourse analysts. For instance, the discourse structure of medical English abstracts has lately been studied (Salager-Meyer 1990) and abstracts have been criticized for being uninformative, misleading and lacking internal structuring. Conference/symposium organizers tend to provide specific guidelines - together with calls for papers - for authors to follow in order to obtain uniformity in abstract structuring. When skimming world congress proceedings, however, one wonders whether the variety of pattems in abstract structuring observed may also be due to cross-cultural preferences. 
In the present article, there has been an attempt that factors which may obscure result interpretation be eliminated: one single genre is examined (abstracts) reflecting one single social occasion (the 9th World Congress of Applied Linguistics at ThessalonikiHalkidiki, Greece, in April 1990). Variation in field of discourse is, thus, eliminated. Mode is another aspect of the communicative dimension of language which, in the present case, is invariant: abstracts are pieces of discourse written to be read. The present research deals with differentiation related to the third communicative aspect of discourse: tenor (Hatim and Mason 1990).

Most of the abstracts written by Greek researchers are written in English. It would have definitely been preferable for us to have examined abstracts by Greek researchers written in Greek rather than in English. Abstracts in Greece, however, are almost always written in Enhlish, even in conference Proceedings where the majority of the papers are written in Greek. It is assumed that the tendencies observed in abstract writing are due to preferences dictated by conventions in the authors' native language, just like various translated EEC documents reflect the style of the original.

The results should be seen relatively. Sharp contrasts should not be expected because most of the Greek researchers have had some acqaintance, to say the least. with the English scientific culture and have, certainly, been influenced by scientific tradition in the English-speaking world.

In this context, it is assumed that even marginal differentiation in writing conventions suffices to identify tendencies between research groups.

Awareness of differences in abstract writing is useful for researchers to be able to conform to the conventions of a target culture or for translators who are required - for instance - to produce abstracts in a target language from source language conference papers. A framework assumed for the analysis of the corpus is the computational theory of discourse structure proposed by Grosz and Sidner (1985), which is an extension of Grice's analysis of utterance meaning accounting - among other things - for discourselevel intentions. The three basic components of discourse structure (linguistic structure, intentional structure, attentional state) deal with different aspects of variation in a discourse. Utterances are the basic elements of linguistic structure. Intentions of a particular sort and a small number of relationships between them provide the basic elements of the intentional structure. Attentional state contains information about the objects, properties and discourse intentions that are most salient at a given point (1985: 3). The intentional structure of discourse, which is going to be focused upon in this article, includes discourse purposes (DPs) and discourse segment purposes (DSPs) which are intended to be recognized and others which are private (1985: 7). These DSPs may be understood as rhetorical purposes, in the sense of the set of mutually relevant communicative intentions (Hatim and Mason 1990: 142) which signal shifts from one division of discourse to another.

The process of linear organization of information in units larger than a sentence has been called thematisation and staging (Brown and Yule 1983: 133-134). By staging. Grimes (1975) is referring to how the linear organization of text can be manipulated to bring certain items into prominence. Crombie (1985), in discussing basic text designs and the way a text is put together. refers to macro-structures, e.g. text designs of a 'situation $>$ problem > solution > evaluation' type. Similarly, Hatim and Mason argue that one of the basic characteristics of text structure is a typical format (or generic structure) which is generalisable and which accomodates a number of actual structures (1990: 171). In a telephone conversation, for instance, the format is: greeting > identification > query. 


\section{DSPS IN ABSTRACT WRITING;}

One form of strictly comparable data, within the interactional function of language, can be found in letter-writing. Discourse analysts have been concerned with what information is represented and how it is thematised, with reference to the type of letter and the intentions of the writer in writing it (Brown and Yule 1983: 150). Within the transactional function of language, abstracts constitute another form of strictly comparable data. In this article. abstracts appearing in the AILA 90) Proccedings are compared and contrasted with respect to the segmentation they exhibit and the author intentions (the ones meant to be recognized) that underlie this segmentation.

The types of papers abstracted have been distinguished so that comparison and/or contrast of abstracts takes place within the same paper category. The criterion for differentiation has been the author's initial purpose (IP) for writing the paper. Absracts have. thus, been classified according to this intention and one of these classes has been focused upon, i.e. abstracts written by researchers who intended to prove some hypothesis with implications in some area within Applied Linguistics; they have achieved this by setting up experiments or by examining data obtained in some other way. One hundred out of one hundred iwenty AILA 90 papers have been written in order to support such an argument on the basis of experimentation or/and examination of data obtained differently.

In what follows, the segmentation and the underlying DSPs of 66 abstracts written by researchers from the English speaking world (USA. Canada, UK, Ireland. Australia, New Zealand) will be shown and compared/contrasted with the DSPs of 34 abstracts written by Greek researchers, mostly in English. (DSPs):

The 100 abstracts examined exhibit the following discourse segment purposes

(a) (Intend A (Inform A R P1)),

where $A=$ author, $R=$ reader and $P 1$ is a set of propositions like the following.

The indexical nature of linguistic behaviour is a commonplace of sociolinguistics. Many studies have shown a significant correlation between listener's evaluation of some speaker's personality trait and, particularly, the vocal aspects of those speakers' speech. However, very few... (All.A Ruqaiya Hasan 1990: 92)

providing background information relevant to the topic dealt with in the paper.

(b) (Intend A (Inform A R P2)).

where $\mathrm{P} 2$ is a proposition like the one below

... of those speakers' speech. However, very few studies have attempled to explore the relationship between informants' impressions about speakers and the semantic aspects of the speakers' natural everyday talk... (Idem.)

describing the problem faced in the paper.

(c) (Intend A (Inform A R P3)),

where $P 3$ is a set of references like the ones in the parentheses below:

The aim of this paper is to discuss how the concept of metaphor as a basic cognitive mechanism involved in the use of language (Lakoff and Johnson 1980; Reddy 1979, et al.), rather as a stylistic device, can account for the creation and maintainance of specific valuedependent images that characterize not only a particular discourse type such as news bulletins. but also reveal our mental categorization and framing (Fillmore 1985) of the world around us. (/d. Sophia Marmaridou: 601) 
providing relevant bibliographical information.

(d) (Intend A (Inform A R P4)),

where $\mathrm{P} 4$ is a proposition specifying the overall aim of the paper like the one below:

...speakers' natural everyday talk. This paper will present some of the findings of an empirical research in this neglected area... (Id. Ruqaiya Hasan; 92)

(e) (Intend A (Inform A R P5)),

where P5 is a set of propositions stating specific goals which are to accomplish the overall aim, e.g.

...The paper first briefly describes and compares the major discourse features of the two genres $[\ldots]$ Then the paper focuses on the first discourse feature in depth, namely, it examines how children handle the co-referentiality and co-classification properties realized... (Id. Christine Pappas: 33)

(f) (Intend A (Inform A R P6)),

where $\mathrm{P} 6$ is a set of propositions specifying the methodology to be followed, e.g.

... The research uses sixteen mother-child dyads (mean age of child 3:8) as stimulus dyads; these were equally divided between iwo social classes. Audio-recording of everyday talk between mother-child dyads was evaluated by 24 listeners... (Id. Ruqaiya Hasan: 92)

(g) (Intend A (Inform A R P7)).

where $\mathrm{P} 7$ is a proposition, like the one below, reporting results

...The results of such an analysis display statistically highly significant correlation between the semantic patterns of a stimulus dyad's dialogue and the evaluation of that dyad by the informants, such that the ranking of the dyads on the two measures - the semantic and the judgemental - is largely isomorphic. (Id.)

(h) (Intend A (Inform A R P8)),

where $P 8$ is a set of propositions promising results, e.g.

...We will present results from evaluations conducted to date of exemplary programs and identify directions for future work in research, evaluation, and teacher preparation (Id. Richard Tucker and JoAnn Crandall: 284 )

(i) (Intend A (Inform A R P9)),

where $P 9$ is a proposition showing usefulness of the research conducted, $e . g$.

...Such comparisons can be useful both in assessing linguistic and ideological influences on children and in the design. implementation and evaluation of educational material. (ld. Evangelos Afendras: 81 )

(j) (Intend A (Inform A R PIO)).

where $\mathrm{PIO}$ is a proposition mentioning open research problems, $e . g$.

...One of the major challenges for teachers and methodologists is to explore ways of enabling learners to progress to a stage where the language is also integrated with their cognitive functioning. (/d. William Littlewood: 258)

(k) (Intend A (Inform A R PII)),

where $\mathrm{PII}$ is a reference list following the abstract. 
Table I shows the segmentation and order of underlying DSPs in abstracts written by researchers from English-speaking countries, whereas Table 2 shows the segmentation and order of DSPs in abstracts written by Greek researchers. Abstracts are represented by an identity number. As observed in Tables 1 and 2:

a. certain DSPs, i.e. providing introductory material (presentation of background information and/or description of the problem) as well as statement of purpose and specific goals, appear at a comparable percentage in abstracts of both groups (see also Table 3), whereas;

b. there are certain DSPs which Greek researchers tend to avoid:

the methodology to be followed in the papers is dealt with less often in abstracts by Greek researchers $(38.2 \%)$. By contrast, the percentage among researchers from English-speaking countries is $62.1 \%$ (column $f$. Tables I \& 2 ).

- $43.9 \%$ of the researchers from the English-speaking world provide bibliographical information in the actual body of the abstract. The percentage is 20.5 among Greek researchers (column c. Tables $1 \& 2$ ).

researchers from the English-speaking world. occasionally $(8.9 \%)$, present a reference list at the end of the absract, whereas Greek researchers tend to omit reference lists altogether (column $\mathbf{k}$. Tables $1 \& 2$ ).

- $18.1 \%$ of the researchers from English-speaking countries indicate the usefulness of their research, whereas the percentage among Greek researchers is lower $(5.8 \%$, column i, Tables 1 \& 2 ).

Consequently, abstracts written by researchers from the English-speaking world exhibit more DSPs. $12.1 \%$ of these abstracts exhibit 6 to 7 DSPs, $62.1 \%$ of them exhibit 4 to 5 DSPs and $25.7 \%$ of them exhibit 3 to 2 DSPs. By contrast, almost half of the Greek researchers restrict themselves to exposing 2 to 3 DSPs, the rest preferring the usual 4 to 5 DSPs. Fig. I is a representation the number of DSPs preferred by research groups.

As shown in the (a)-(k) DSP inventory above, there is a set of options researchers select from in abstract writing. There are, also, levels of generality to be distinguished with respect to these options: stating the purpose of the research and, possibly. making an introduction for the purpose to be stated are the primary/general concems of the researcher in writing an abstract. This can be supported by the fact that whenever a statement of purpose is absent from the body of an abstract, in the present corpus, the information about the purpose of the research is conveyed by the title: otherwise Grice's maxim of relevance would have been flouted (Levinson 1983: 102). Stating specific goals, describing methodology or reporting results are pieces of information of a more specific kind. Discussing the usefulness of the research conducted and providing reference lists is information at an even higher level of specificity.

Given the generalisation/specification bounds of certain types of discourse (Perhaps each type of discourse, given a certain topic of conversation, has an UPPER BOUND of generalization and a LOWER BOUND of particularization or specification (van Dijk 1977: 109)), it is observed that researchers from English-speaking countries tend to allow a higher degree of particularization (the particularization bound is lowered) by including methodological and bibliographical information, description of specific goals and usefulness of the research conducted. By contrast, the degree of generalization allowed by researchers of both groups is comparable, as shown in Table 3 . Greek researchers, that is, take the notion of selective incompleteness (A discourse may omit reference to certain facts $/ .$. / because these facts were not 'relevant' in the conversational context (van Dijk 1977: 109)) more seriously by restricting themselves to exposing more general DSPs. 
Unlike DSP selection, ordering is not subject to cross-cultural variation. In Grosz and Sidner's model, two structural relations between DSPs have been identified, dominance and satisfaction-precedence. Some DSPI may contribute to DSP2 and, conversely, DSP2 may dominate DSP1. For some discourses the order in which the DSPs are satisfied may be significant. as DSP1 may satisfaction-precede DSP2 (1985: 8). In the AILA 90 sample, the dominance relatioships for the DSPs are more or less comparable, as shown in Tables 1 and $2, e . g$.

- the authors' intention to provide introductory material (presentation of background information and statement of the problem) usually satisfaction-precede (: should be satisfied before another DSP) statements of purpose $(66.5 \% \mathrm{vs} .61 .7 \%)$, whereas, occasionally, stating the purpose may satisfaction-precede the author's intention to provide introductory material ( $31.8 \%$ vs. $32.8 \%)$ : hierarchy:

stating specific goals and results never appear first in the DSP dominance

- whenever a satisfaction-precedence relation exists between the DS providing background information and the DS which states the problem, the DS boundary between them is always marked by a contrastive connective (see however in (b) of the (a)-(k) DSP inventory shown above).

Abstracts seem to be second-order informativity (de Beaugrande and Dressler 1981: 143) text types allowing a relatively high level of predictability so that the reader be left with easily manageable processing load. There are particular function words and expressions (contrastives, enumerators, etc.) which facilitate processing. In fact, the relatively invariant DS ordering observed seems to be a reason for this predictability. In this respect, abstract writing resembles a slot-filling exercise.

Variability in the DSP selection between the two cultural groups, on the other hand, relates to the pragmatic dimension of language since it is a matter of a different perlocutionary effect intended by the authors: restricting oneself to exposing the most general DSPs (purpose, introductory material - if necessary - and results) creates 'suspense' as to what the in-between details may be. It is a 'story-telling' attitude, mostly preferred by Greeks. echoing the interactional aspect of language use. By contrast, providing more factual information (methodological, bibliographical, etc.), may eliminate 'suspense'; it is a more descriptive attitude (Lyons 1977: 591) echoing the transactional aspect of language use.

\section{DISCOURSAI. FEATURES IN ABSTRACT WRITING;}

Hatim and Mason maintain that abstracts are written to be read and normally display a neutral functional tenor (1990: 51). In reading the AILA 90 abstracts, however. one observes that the researchers' expression has varied impact on the reader and that what varies is mainly the author's attitude towards the text and the readership. It has been anticipated that the participants in the social e'vents which are reflected in genres are bound to be involved in attitudinally determined expression characteristic of these events (1990: 70). In this section, the authors' angle will be examined: attitudinal variation on the part of the author will be examined with reference to the cultural group the author belongs to. Contrasts may not be sharp so as to constitute totally different cultural codes but they do indicate attitudinal tendencies between research groups. Although abstracts relate to the transactional function of language, Brown and Levinson's interactional model (1987) will prove useful for the study of these attitudinal tendencies, since some kind of interaction is actually intended to take place. 
In the corpus, there are certain linguistic devices used for the expression of the various DSPs which encode particular author attitudes. In discussing politeness, Brown and Levinson indicate language phenomena involved in constructing linguistic realizations of positive and negarive politeness strategies (1987: 27) which minimize and maximize respectively - social distance. Impersonalizing and passivizing, for instance, allow the speaker to avoid direct reference to the agent and has been considered a linguistic realization of a negative politeness strategy. The speaker does not want to impinge on the hearer by avoiding the $I$ and you pronouns.

\section{'I'/'WF' PERSONALIZATIONS}

Impersonalizing and passivizing are common devices in both groups:

...The srudy, thus, show's quantitative and qualitative changes... (ALLA 1990: 453)

...it has be'n show'n that helping children... (/d.: 72)

...Frequencies of distribution of the words in the corpus were estimated... (Id:: 81)

..The stated aim is addressed by investigating (/d.: 59.3)

I/we personalizations, which minimize social distance as positive politeness devices, are considerably fewer in both groups, but they are more frequent in abstracts written by Greek researchers $(26.4 \%)$

In this paper / will report research concerning... (/d:: 611)

...I will lest the hypothesis that $|\ldots|$ / will further take up the question whether... (Id.: 612)

.... n'e shall be concerned with the way in which language is used... (/d.: 206)

...in this paper ne first examine $|. .$.$| Second. we make a multivariate qualitative analysis of$ such borrowings... (ld: : 131$)$

Half of the occurrences of the $/$ pronouns appear in pluralized form. Since these pluralized we/our expressions appear in abstracts written by ONE single author each time, it can be concluded that it is the inclusive (: both author and reader included in the activity) type of we pronoun used. By contrast, abstracts written by researchers from the English-speaking world containing occurences of/we expressions are fewer $(13.6 \%)$ :

...I will foc us on three areas of difficulty within the systemic-functional model:... (Id.: 228) ... ne recall that it was rooted in the notion that $|\ldots|$ we helieve that it will be possible to cast sone light on the workings of ungrammaticality... (/d.: 424);

in fact, the percentage is lower $(12 \%)$ if it is to be taken into consideration that certain of the n'e expressions appear in abstracts written by co-authors, as in:

In this paper w'e reanalyze data initially presented in $[\ldots]$ We argue that we cannot assume... (ld: 4.30$)$

We expressions are realizations of a positive politeness strategy, since authors attempt to minimize social distance by implicating group membership: author and readership are presented as participating in the activity.

Similarly, Sifianou (1989: 534) in discussing verifying interlocutors in telephone conversations in England and Greece, argues that English are negative politeness persons preferring overt identification of the caller (the English insistence on overt identification could be interpreted as an example of negarively polite linguistic pessimism...) whereas Greeks may adopt positive politeness behaviour (...lack of owert identification in Greek can be interpreted as an example of linguistic optimism, a clearly positively politeness device. dircered towards the addressee's pesitive face). 


\section{ILLOCUTIONARY FORCE WEAKENERS}

Yet, Greek researchers should not be considered as purely positive politeness persons. They also seem to be fond of devices which have been considered realizations of a negative politeness strategy.

Greek researchers, for instance, show a greater tendency in using weakeners (: expressions which soften and tentativize what they modify) in stating purpose and results of research or presenting problems. Brown and Levinson, in discussing negative politeness devices with respect to Grice's Maxims, make reference to quality hedges which may suggest that the speaker is not taking full responsibility for the truth of his utterance (1987: 164). $20 \%$ of the Greek researchers felt the need to use the 'seem hedge' in stating conclusions and problems, c.g.

...the reading process at this stage does not seem to rely heavily on $|\ldots|$ In addition. ir seems likely that... (A/LA 199): 52)

...A closer inspection $|\ldots|$ seem.s to drive lowards the conclusion that $|\ldots|$ this seem.s $t o$ imply that $|\ldots|$ For example, male intruders seem 'o often $|\ldots|$ women, on the other hand se'm at a first... (/d.: 204-205)

...But they have, it seems, fallen into deterministic position... (/d.: 212)

... women $\mid$... I seem to have come a long way $\mid$... | which. even nowadays, still seems to be more acceptable as a male trait. (/d.: 21.3)

.. The acquisition of Greek did nof se'em to differ from the ... (Id.: 492)

... whereas Greeks do not seem to care much for such things... (Id:: 6|2)

whereas only $7.5 \%$ of the researchers from English-speaking countries did this. e.g.

...but they seem to have existed before the... (/d: 18.5)

.. There is it seems to me no way of engaging in ferninist or any other kind of linguistic and cultural critique... (/d.: 228)

...It seems that if the answer to a question $|\ldots|$ is affirmative then a single 'yes' will be appropriate... (/d.: 366), ctc.

Another weakener, used by Greek researchers. which hedges illocutionary force of expressions is the 'attempt hedge'. Greek researchers show a greater tendency in avoiding making promises about whether the purpose of the paper is being fulfilled. $20.5 \%$ of them prefer weakening the illocutionary force of the expressions which state purposes, e'.g.

...The paper attempts to investigate if and to what extent ... (/d : 201)

...In an effort to investigate $|\ldots|$ an analysis of the discourse of the two $|\ldots|$ will be attempted in the paper $(l d: 205)$

...An attempt will be made to describe the language of ... (ld.: 206)

This paper attempts to investigate the effect of gender... (/d::213)

...the two languages are in foct much closer together than Modern Gireek and Modern

English, as this paper will attemp/ to show. (/d.:28.3)

...All attempl will be made to isolate the conjunctive category in English... (/d.: 591)

whereas only $6 \%$ of the authors from the English-speaking world did this:

...This paper will at/empl to identify the skills and strategies involved in negotiation (ld: $29(1)$

Other weakeners are occasionaly employed by both groups

...It is precisely the disagreeing habits $[. .$.$] that this study wishes to record under the predic-$ tion that... (ld.: 213)

...Although variation insofar as it is random escapes explanation by definition, we believe it will be pessible to cast some light on the workings of ... (/d.: 424) 
... The paper maintains that, as such students begin tertiary studies, they may need support in their efforts to... (/d: :394)

While the majority of the researchers in both groups, that is, avoid weakeners in stating conclusions, purposes or problems (e.g. the following DS could have read seem to reveal instead of reveral)

...These responses reveral some distinct clusters of beliefs. Among Chinese students $47 \%$ believe that... (ld.: 428)

Greek researchers show a greater tendency in weakening their commitment to the truth of certain expressions, thus adopting a negatively polite attitude.

\section{DIRECT QUESTIONS}

A different attitude is also adopted when it comes to exposing the purpose of the research or the specific goals the author is going to pursue. In the sample, this is often achieved by direct or indirect questioning:

...One might ask: Initially. how does an infant begin to derive meaning from the language to which he or she has been exposed? From where do the first conceptual responses come? How does verbal utterance come to have meaning for a child who at the outset, has only a potential for acquiring language, but yet no language?... (/d:: 35)

. The main question is: can we see Montreal Greek evolving to a social and regional dialect per se?... (/d:: 131)

... This paper attempts to investigate if and to what extent the linguistic strategies which have been proposed in the past twenty-five years as characteristic of men and women are torme out by our dala... (Id.: 201)

Conventional indirectness has been identified as a negative politeness device (1987: 132) together with the use of rhetorical questions (: How was / to know'...? (c.i. I wasn't), 1987: 223).

The direct questions in the sample examined differ from rhetorical questions in that no answer is implicated (as in the parenthesis above). The author does break a sincerity condition on questions - since s/he does not expect an answer - in the same way the speaker does in the rhetorical question situation, but in the abstract writing situation there is some expectation for interaction during the delivery of the paper, which may prove helpful for answering these questions. The author appears optimistic about obtaining an answer to the question $s /$ he poses, i.e. adopts a positive politeness strategy and acts as if the readership is able/willing to participate in the activity.

In both groups, authors using direct questions in the DSs are relatively few compared to those preferring indirect questions. Greek researchers, however, show a relatively greater tendency $(14.7 \%)$ in exhibiting this positively polite linguistic optimism, than researchers from English-speaking countries ( $9 \%$ ).

Attitudinal variation on the part of the author has been examined cross-culturally with reference to phenomena which have, in fact, been anticipated in Brown and Levinson's interactional model: //u'e personalizations, illocutionary force hedges and direct questions. In the following subsection, the authors' attitude will be examined with respect to a phenomenon which could not have been dealt with in an interactional model since it relates to writing conventions. 


\section{PARAGRAPH STRUCTURING;}

Brown and Yule (1983: 99) argue that paragraph structuring is genre-specific and that it would be appropriate for discourse analysts to describe the structure of an orthographic paragraph format in terms of the deviation from some 'true' paragraph structure of what is being written, thus, defining the 'norms' or regular features of paragraph organisation in these genres. It appears that paragraph structuring within the same genre is also culture-specific: the number of paragraphs. in the abstracts of the $A / L A 90$ sample examined, differs cross-culturally and, consequently, the DSP organisation in an orthographic paragraph varies accordingly.

As far as the number of the paragraphs is concerned a little more than half of the researchers, in both groups, prefer 3/4-paragraph abstracts $(27.2 \%$ of the researchers from English-speaking countries prefer 3-paragraph abstracts and $31.8 \%$ of them prefer 4-paragraph abstracts. The percentage among Greek researchers is $32.3 \%$ for either 3 - or 4-paragraph abstracts). Similarly, the ratio of those preferring 2-paragraph abstracts is comparable ( $19.6 \%$ vs. $17.6 \%$. respectively). The two groups differ in their preferences concerning 1-paragraph and 5-paragraph abstracts: Greek researchers hesitate to write 1 -paragraph abstracts (3\%), whereas researchers from English-speaking countries do less $(19.6 \%)$. By contrast, researchers from the English-speaking world show the least preference $(6 \%)$ in 5 -paragraph abstracts, whereas Greek researchers do not seem to consider 5-paragraph abstracts 'taboo' $(14.7 \%)$. The histogram in Fig. 2 is a representation of the preferences exhibited by the two cultural groups, concerning the number of paragraphs in the sample examined: researchers from English-speaking countries are less concerned about dividing their abstracts into paragraphs whereas Greek researchers show a greater preference in doing this.

As far as the relation of DSPs to paragraphs is concerned, orthographic paragraphs in the sample very often contain more than one or two DSPs. There are, however. cases when a DSP extends over more than one or two orthographic paragraphs: this is a tendency more common among Greek researchers $(25.7 \%$ vs. $41 \%)$.

If Brown and Levinson's interactional model were to be extended to written discourse, such a tendency could be considered a negative politeness device, since the author is being 'pessimistic' by not assuming that the readership would be able to follow his/her intended DSP structure (DON'T ASSUME H IS ABLE/WILLING TO DO A, an aCt required of him (1987: 145)) and, therefore, would use writing conventions (e.g. paragraphs) as a device which would enable him/her to be analytic, thus, facilitating comprehension.

\section{CONCLUSION}

A sample of 100 abstracts written by researchers from English-speaking countries and Greece has been examined with respect to the selection of the DSPs made by the authors and the ordering of these DSPs. The two cultural groups examined exhibit different DSP selection preferences but similar DSP ordering: researchers from Englishspeaking countries tend to include more information about their research in the abstract, by including more DSPs, whereas Greek researchers appear more selective in exposing their DSPs. The DSP dominance hierarchy, on the other hand, is similar in the two groups. The majority of the abstracts in the sample exhibit the following dominance relationships: providing introductory material (presentation of background information and/or problem statement (DSP1)) is usually dominated by statement of purpose (DSP2), which satistaction-precedes statement of specific goals (DSP4) and/or methodological information (DSP3). Reporting or promising results (DSP5) almost always appears at the end. 
From the point of view of the Greek authors, it is as if providing more information about author intentions, as researchers from the English-speaking world do, destroys the suspense and the excitement of the interaction expected and, thus, omitting more specific DSPs is preferred. The interactional aspect of language use is underlined here, whereas including more factual information makes researchers from the English-speaking world appear more transactional in their attitude towards abstract writing.

The $1(X)$ abstract sample has also been examined with reference to the politeness strategy the authors adopt towards the readership, i.e.

- whether the authors are interested in implicating that the reader is actually considered as participating in the research activity (l/we personalisations), being able/willing to peform acts required of him/her (by the author assuming that the reader could or would be willing to answer questions posed by the author directly);

- whether the authors feel free to promise that their research will come to a particular conclusion (by avoiding illocutionary force hedges (seem) in stating or promising results) or implicating that their reasearch will successfully fulfill its purpose (by avoiding illocutionary force weakeners (attempt) in stating purposes), and;

- whether the authors intend to facilitate the reader in his/her following the thread of discourse (by allowing more paragraphs) presupposing that the readership would not be able/willing to spend much energy on trying to follow what the author has in mind.

Concerning the author attitude towards the text and the readership as described by the above points, the two groups differ in that they show comparatively stronger/weaker tendencies - though sometimes marginally - in adopting a positive/negative politeness behaviour: (a) //w'e personalizations and (c) direct questioning show Greek researchers to be willing to adopt a more positive politeness behaviour than researchers from the English-speaking world, whereas (b) the use of illocutionary force hedges and (d) paragraph structuring show Greeks to be willing to adopt a more negative politeness attitude when compared to their fellow-researchers from English-speaking countries. What is important, I would think, is that balance between positively/negatively polite attitudes is secured in both groups.

The relationship between author and readership, reflected in choices like the ones described above, is a matter of tenor (level of formality, relative distance, etc.); it is, in fact, an aspect of language use to be taken into account during translation between English and Greek. It appears that the translator, in attempting to respect discoursal habits in the target language, may not need to affect the cohesive progression of the source text (though some alterations concerning DSP selection may have to be made) but s/he should rather consider choices like im/personalizing, in/direct questioning, illocutionary force weakening/strengthening, paragraph structuring, which reflect the relationship between author and readership in the target language.

REFERENCES

AlLA 90 (iREECE Procededings (1990): I \& 2, 9th World Congress of Applied Linguistics, ThessalonikiHalkidiki, Greece. April 15-21.

BEAUGRANDE. R. de and W. DRESSLER (1981): Imrodurfion to Text Lingustics, London. Longman.

BROWN, P. and S. IEVINSON (1987): Politeress … Some Unversals in Langhage Usage, Studies in Interactional Sociolingustics 4, (ambridge. (ambridge University Press.

BROWN, (i. and $G$. Y IILE (19K.3): Discourse Anulysis, Cambridge. Cambridge Universily Press.

CROMBIE, W. (1985): Process and Relatton in I)ixcourse' and Language Le'arning. Oxford. Oxford University Press.

GRIMES. J. E. (1975): The Thread of Discourse. The Hague, Mouton.

GROS7. B. and C. SIDNER (1985): The Structures of Dsscourse Srructure. Center for the Study of Language and Information, Report n" CSL1-85-39. Stanford CA. Stanford Iniversity.

HAI.I.IDAY. M. A. K. and R. HASAN (1976): (whe'sion in Finglish. I.ondon. I.ongman. 
HATIM. B. and I. MASON (1990): Discourse and the Translator, Language in Social Life Series, London, Longman.

LEVINSON, S. (1983): Pragmatics, Cambridge, Cambridge University Press.

LYONS, J. (1977): Semantics, 1 \& 2. Cambridge, Cambridge University Press.

SALAGER-MEYER, F. (19\%)): "Discoursal Flaws in Medical English Abstracts: a Genre Analysis per Research-and Text-type", Text, vol. I(O(4), pp. 365-384.

SIFIANOU, M. (1989): "On the Telephone Again! Differences in Telephone Behaviour: England Versus Greece", Language in Society. 18(4), pp. 527-544.

VAN DIJK. T. A. (1977): Texi and Comter. Explorations in the Semantics and Pragmatics of Discourse, London. Longman.

WOODS, A.. FLETCHER. P. and A. HUGHES (1986): Statistics in Language Studies, Cambridge, Cambridge University Press. 
TABLE 1 - ORDERING; OF DSPS: ABSTRACTS WRITTEN BY RESEARCHERS FROM THE ENGIISH-SPEAKING; WORI,D

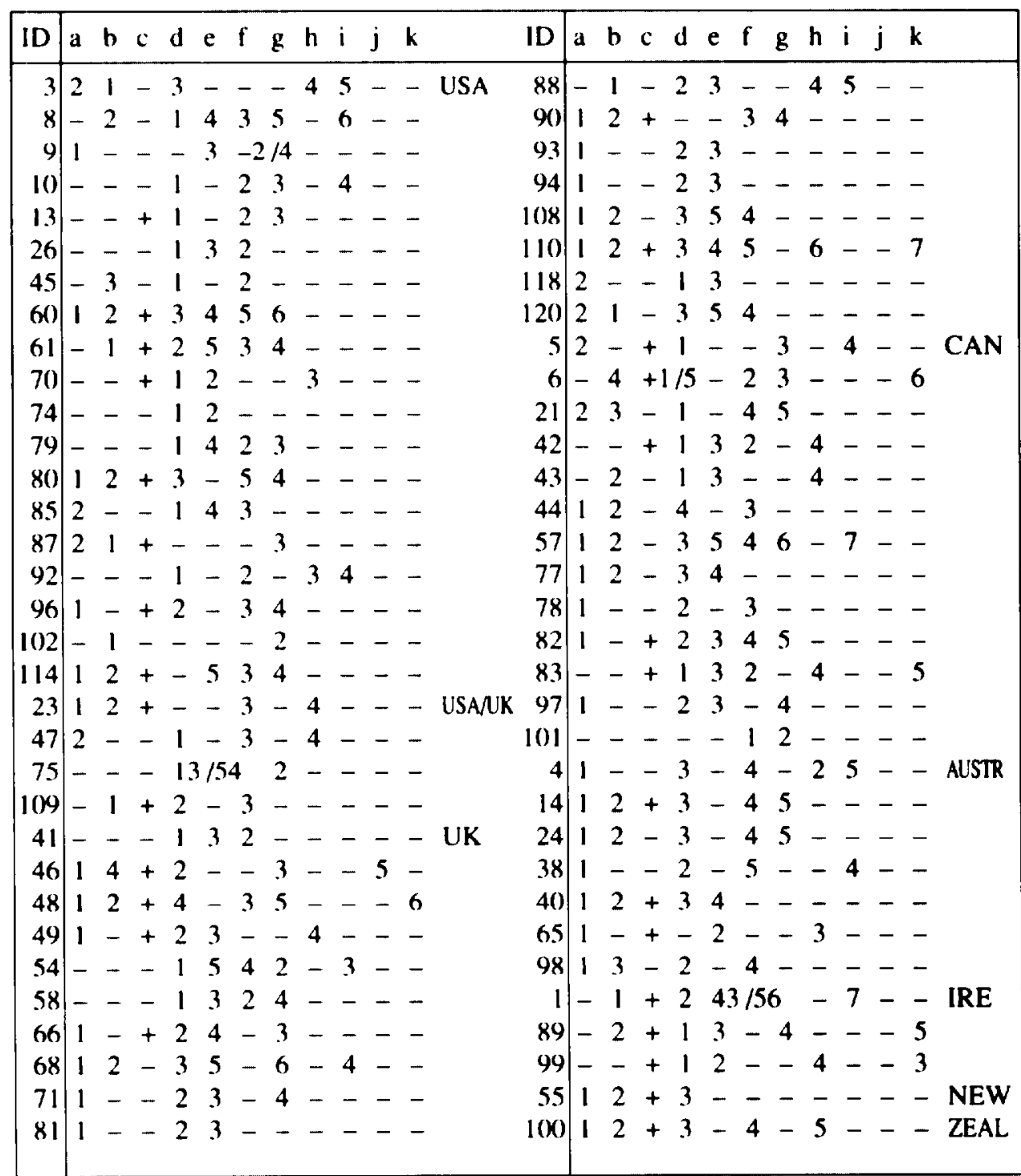
a: background information
b: description of problem
c: bibliographical information
d: purpose
e: specific goals
f: methodology
g: results reported
h: results promised
i: usefulness of research
j: open research problems
$\mathrm{k}$ : reference list 
TABLE 2 - ORDERING OF DSPS: ABSTRACTS WRITTEN BY GREEK RESEARCHERS

\begin{tabular}{|c|c|c|c|c|c|c|c|c|c|c|c|c|c|c|c|c|c|c|c|c|c|c|c|}
\hline ID & $\mathbf{a}$ & b & c & $\mathrm{d}$ & e & f & $\mathbf{g}$ & h & $\mathrm{i}$ & J & k & ID & $\mathbf{a}$ & b & c & d & e & & g & 1 & & & k \\
\hline 2 & - & 1 & - & 2 & 3 & 5 & 4 & - & - & - & - & 59 & 1 & 2 & - & 4 & 3 & - & - & & & & - \\
\hline 7 & - & - & - & 1 & 3 & 2 & 4 & - & - & - & - & 67 & - & - & - & 1 & 2 & - & 3 & - & & & - \\
\hline 11 & - & - & + & 2 & - & I & 3 & - & 4 & - & - & 69 & 2 & 1 & - & 3 & 4 & - & - & - & & & - \\
\hline 12 & 1 & 2 & - & & - & 3 & 5 & - & - & - & - & 84 & - & 1 & - & 2 & - & _ & 3 & & & & - \\
\hline 16 & 1 & 2 & - & - & - & - & 3 & - & - & - & - & 86 & - & 1 & - & 3 & 2 & _ & - & & & & - \\
\hline 18 & 1 & 2 & + & 3 & 4 & - & - & - & - & - & - & 91 & 1 & - & - & 2 & - & - & 3 & & & & - \\
\hline 20 & 1 & 2 & - & 3 & - & - & - & - & - & - & - & 95 & - & - & - & 1 & - & 2 & - & 3 & & & - \\
\hline 22 & 2 & - & + & 1 & - & - & 3 & - & - & - & - & 105 & 2 & - & + & - & 1 & 3 & - & & & & - \\
\hline 28 & - & 2 & - & 3 & - & 1 & - & 4 & - & - & - & 106 & - & 1 & - & - & _ & - & - & & & & - \\
\hline 32 & 1 & 2 & - & 3 & 4 & 6 & - & - & 5 & - & - & 107 & 1 & - & + & 2 & - & 3 & _ & & & & - \\
\hline 33 & 1 & - & - & 5 & - & 3 & $2 / 4$ & & - & _ & - & 111 & - & - & + & 1 & 2 & - & - & & & & - \\
\hline 34 & 1 & 2 & - & 3 & - & - & 4 & - & - & - & - & 112 & - & - & - & 1 & 3 & 2 & - & & & & - \\
\hline 36 & 1 & 2 & - & 3 & - & - & - & - & - & - & - & 113 & - & - & + & 1 & - & 2 & 3 & & & & - \\
\hline 37 & 2 & 3 & - & 1 & - & - & - & 4 & - & - & - & 115 & - & - & - & 1 & 2 & - & 3 & & & & - \\
\hline 50 & - & - & - & 1 & - & - & 2 & - & - & - & - & 116 & 1 & 2 & - & - & - & - & 3 & & & & - \\
\hline 53 & 1 & - & - & 2 & 4 & 3 & 5 & - & - & - & - & 117 & 1 & 2 & - & 3 & 4 & - & 5 & & & & - \\
\hline 56 & 1 & - & - & - & - & - & 2 & - & - & 3 & - & 119 & 1 & 2 & - & - & 3 & - & - & & & & - \\
\hline
\end{tabular}

TABLE 3 - PROPORTION OF DSPS PER RESEARCH GROUP

\begin{tabular}{|l|c|c|}
\hline \multicolumn{1}{|c|}{ DSPs } & $\begin{array}{c}\text { English-speaking } \\
\text { countries }\end{array}$ & Greece \\
\hline background information & & \\
and / or problem & $77.2 \%$ & $70.5 \%$ \\
purpose & $86.3 \%$ & $85.2 \%$ \\
results reported & $50 \%$ & $52.9 \%$ \\
& & \\
methodology & $62.1 \%$ & $38.2 \%$ \\
specific goals & $57.5 \%$ & $44 \%$ \\
bibliographical inform. & $43.9 \%$ & $20.5 \%$ \\
reference list & $8.9 \%$ & $0 \%$ \\
results omitted & $25.7 \%$ & $20.5 \%$ \\
usefulness & $18.1 \%$ & $5.8 \%$ \\
open resarch problems & $1.5 \%$ & $2.9 \%$ \\
\hline
\end{tabular}



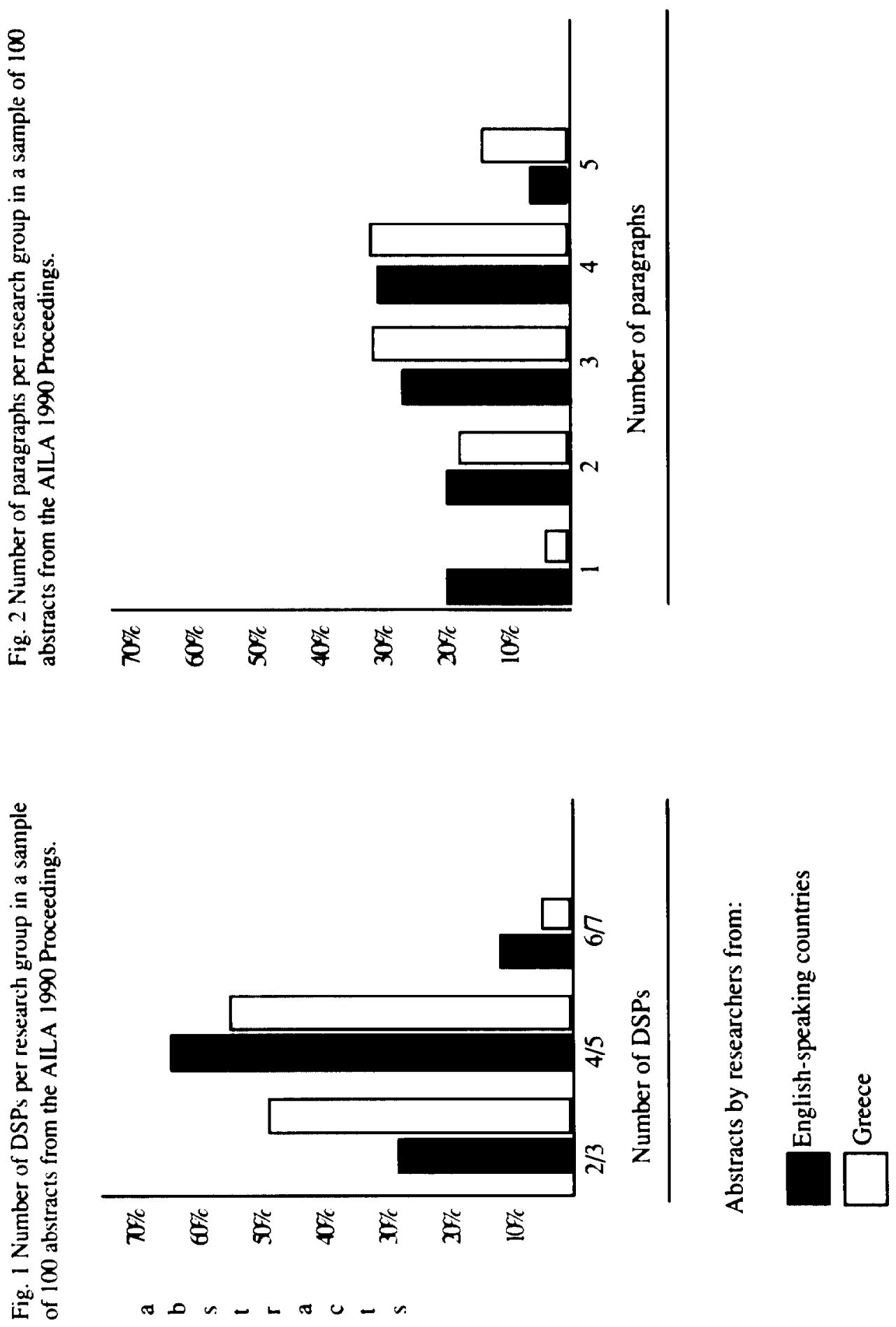